\title{
Chirripó Hydrological Research Site: advancing stable isotope hydrology in the Central American Páramo
}

\author{
Germain Esquivel-Hernández ${ }^{1}$, Ricardo Sanchez-Murillo ${ }^{1}$, and Enzo Vargas-Salazar ${ }^{2}$ \\ ${ }^{1}$ Universidad Nacional de Costa Rica \\ ${ }^{2}$ Costa Rican National System of Conservation Areas
}

January 27, 2021

\section{Introduction}

Tropical mountainous ecosystems are recognized as providers of valuable ecological and hydrological services (Viviroli et al, 2007). In Central America, the Páramo, a high-elevation tropical grassland ecosystem, extends over $200 \mathrm{~km}^{2}$ in Costa Rica and Panama, with $~ 50 \%$ of this area located within the Chirripo National Park between 3,100 and $3,820 \mathrm{~m}$ asl (-83.49deg, 9.46deg). Vegetation mostly consists of 0.5 to $2.5 \mathrm{~m}$ tall bamboo dominated (Chusquea subtessellata) grasslands, covering up to $60 \%$ of the total Paramo area in Costa Rica (Fig.1a). The climate is controlled by the northeast trade winds, the latitudinal migration of the Intertropical Convergence Zone (ITCZ), cold continental outbreaks (i.e., northerly winds), and the seasonal influence of Caribbean cyclones. These circulation patterns produce two rainfall maxima on the Pacific slope, one in June and one in September, which are interrupted by a relative minimum between July-August, known as the Mid-Summer Drought, due to intensification of trade winds over the Caribbean Sea (Magana et al., 1999; Waylen, 1996). The wettest season extends from May to November (contributing up to $89 \%$ of the annual precipitation), whereas the driest season is from December to April (Fig. 2a; Esquivel-Hernandez et al., 2018). The surface water system of Chirripo is characterized by a lake district which comprises approximately 30 lakes of glacial origin and streams flowing down the Caribbean and Pacific slopes (Fig 1b). Lake catchments are characterized by steep slopes that promote rapid hydrological responses such as fast water-level changes. Input of water to these glacial lakes is mostly controlled by the seasonal inputs of rainfall, which mix up with stream and subsurface waters. In April 2015, the Chirripo Hydrological Research Site (CHRS) was installed with the goal of advancing the understanding of the hydrological functioning in the Central American Paramo using environmental tracers (i.e., water stable isotopes) in combination with hydrometric data. A detailed map of CHRS is available in Esquivel-Hernandez et al. (2019).

\section{Methods}

\subsection{Collection of precipitation and surface water samples}

Daily precipitation samples ( $\mathrm{N}=512$ ) were collected at the Base Crestones shelter (-83.480deg, 9.460deg, $3,400 \mathrm{~m}$ asl) on the Pacific slope of Chirripo using a passive collector (Palmex Ltd., Croatia). Samples were collected manually on every rainy day at 07:00 hr (-06:00 GMT). Lake water samples were collected at Lake Chirripo (-83.494deg, 9.483deg, 3,524 m asl, $\mathrm{N}=48$ ), Lake Ditkevi (-83.481deg, 9.469deg, 3,506 $\mathrm{m}$ asl, $\mathrm{N}=$ 66 ), and Morrenas Lakes (-83.486deg, 9.492deg, 3,495 m asl, $\mathrm{N}=38$ ) following a roughly biweekly sampling plan. Lake water samples were manually collected from about $20 \mathrm{~cm}$ below the surface and $\sim 25 \mathrm{~m}$ away from surface stream inlets. Stream water $(\mathrm{N}=74)$ was collected at several sites where surface water was flowing into the lakes or into the main channelized stream of CHRS (Talari River, -83.503deg, 9.458deg, 3,352 m asl).

\subsection{Stable isotope analysis}


Stable isotope analyses of precipitation and surface water samples were conducted at the Stable Isotopes Research Group facilities of Universidad Nacional (Heredia, Costa Rica) using a cavity ring down spectroscopy water isotope analyser L2120-i (Picarro, USA) and a LWIA-45-EP water isotope analyzer (Los Gatos, USA). ${ }^{18} \mathrm{O} /{ }^{16} \mathrm{O}$ and ${ }^{2} \mathrm{H} /{ }^{1} \mathrm{H}$ ratios are presented in the established delta notation $\delta$ (scale. Deuterium excess was calculated as $d$-excess $=\delta^{2} \mathrm{H}-8 \cdot \delta^{18} \mathrm{O}$ (Dansgaard, 1964). The analytical long-term uncertainty is \pm 0.5 and \pm 0.1

\subsection{Meteorological data and lake water temperature}

Due to the remoteness of CHRS, there is a limited access to internet resources. Between April-August 2015, we only registered precipitation amounts (mm/day) using a tipping bucket (Oregon Scientific, USA) installed at the Base Crestones shelter. Between September 2015 and December 2017, relative humidity (\%), air temperature $\left({ }^{\circ} \mathrm{C}\right)$, and precipitation amounts $(\mathrm{mm} / \mathrm{hr}$ ) were recorded using a LW301 weather sensor kit (Oregon Scientific, USA). In January 2018, when the Internet connectivity in the shelter was improved, a Vantage Pro2 weather station (Davis Instruments, USA) was installed to register the meteorological conditions at CHRS. Between September 2015 and November 2020, the lake water temperature was recorded at 15-min intervals by an Onset HOBO water temperature data logger installed at the west bank of Lake Ditkevi. Water temperature was also manually registered for some lake and stream water samples collected between September 2015 and December 2018 using a field portable tester (Hanna Instruments, USA).

\section{The need to advance the hydrological research in the Central American Paramo}

High-elevation tropical ecosystems like the Paramo are susceptible to potential impacts of changes in climate and land cover which could affect the variability in their hydrological conditions and ecohydrological functional properties (Esquivel-Hernandez et al., 2017; Wright et al., 2017). Overall, the information about the importance of Paramo ecosystem was identified much earlier in South America than in Central America which led to a more structured research in the Andes compared to Central America (Correa et al., 2020). Therefore, the isotopic and hydrometric information collected at CHRS can help define and promote future hydrological research in tropical montane ecosystems and can endorse adaptation policies to alleviate the impacts of potential changes in the water balance of the Paramo and the lowlands that rely on its water supply.

\section{Research findings and applications}

To our knowledge, CHRS is the only hydrological research site situated above the tree timberline (i.e., $>3,000-3,100 \mathrm{~m}$ asl) in the Central American and Caribbean region. The Central American region is transected by a NW-SE mountain range that divides the region into the Caribbean and Pacific slopes with similar precipitation regimes (Sanchez-Murillo et al., 2020a). The unique geographic location of Costa Rica within this mountainous region, with moisture inputs from the Caribbean Sea (windward) and the Pacific Ocean (complex leeward topography), offers an ideal scenario for the use water stable isotopes to develop hydrological research (Sanchez-Murillo et al., 2020b).

Combined analysis of air mass back trajectories and the temporal precipitation isotopic variations for CHRS revealed the effective contribution of maritime moisture from the Caribbean Sea (90\% frequency) and the Pacific Ocean (10\% frequency), with the preferential contribution from the Caribbean due the influence of the north-east trade winds travelling over the central and south-eastern Caribbean Sea towards CHRS (Fig 2b,c; Esquivel-Hernandez et al., 2019). CHRS data are also key to identify inputs from the central Pacific Ocean and local evapotranspiration fluxes. Overall, as water vapour encounters the main mountain range, orographic distillation and convergence increase, resulting in depleted precipitation arriving from the Pacific domain (Fig 2b; Sanchez-Murillo et al., 2020a). The lesser contribution of recycled water vapour arriving at CHRS is indicated by the $d$-excess variations in precipitation $(d$ - excess values $>10$

The first isotopic characterization of the surface water system of CHRS indicate that the evaporation conditions in the glacial lakes are highly influenced by input from precipitation that is in isotopic equilibrium with local water vapour, yielding low evaporation to inflow ratios $(<20 \%$, Esquivel-Hernandez et al., 2018). 
Due to their position near the equator and high elevation, lake water temperature of Lake Ditkevi shows seasonal variations but weak thermal stratification (Fig. 2a). Overall, the attenuation effect observed in the isotopic composition $\left(\delta^{18} \mathrm{O}\right)$ and $d$-excess of lake water most likely resulted from the relatively long residence times of precipitation, stream, and subsurface water (Fig. 2b,c). However, when compared to precipitation, lake and surface water reflects the evaporation effects as the corresponding evaporation lines (ELs) diverge from the local meteoric water line (LMWL) of the study region (Fig. 3). Therefore, because of the isotopic enrichment, the slopes of the ELs fall between the slope of the LMWL and the slope of local evaporation line (LEL) calculated using pan evaporation data (Fig.3; Esquivel-Hernández et al., 2018).

The intensity of sources or sinks of methane remain critically understudied in high elevation biomes and scarce data are currently available in the literature for the neotropical Páramo ecosystems. CHRS meteorological data were essential to identify key drivers of methane fluxes in soils of the Chirripó National Park. Overall, the identified soil and vegetation gradients revealed that sites without drainage-impeding soil layers or with the facilitating presence of vigorous Chusquea vegetation led to relatively stronger sinks of methane as compared to fields with wetter, less aerated soils (Chai et al., 2020). CHRS data has also served as baseline information to improve the limited paleoclimate data in Central America and to provide reliable estimates of hydroclimate and environmental change in this region (Wu et al., 2019a,b).

\section{Data availability statement}

The hydrologic data of the Chirripó Hydrological Research Site collected between April 2015 and November 2020 are publicly available at http://hdl.handle.net/11056/18825. Summary statistics of the dataset are shown in Table 1. For more information on the available datasets, please communicate with the lead author germain.esquivel.hernandez@una.ac.cr.

\section{Acknowledgements}

The authors would like to thank the administration and park rangers of the Chirripó National Park (Costa Rican National System of Conservation Areas, SINAC) for their valuable help with the collection of daily precipitation samples and weekly surface water samples; the access to the research site; and the logistical support. GEH and RSM. also thank the Research Office of the National University of Costa Rica through Grants SIA-0482-13 and SIA-0101-14, and the support by the International Atomic Energy Agency Grant CRP-19747 under the initiative "Stable isotopes in precipitation and paleoclimatic archives in tropical areas to improve regional hydrological and climatic impact models".

\section{References}

Chai, L.L., Hernandez-Ramirez, G., Hik, D.S., Barrio, I.C., Frost, C.M., Chinchilla-Soto, C., EsquivelHernandez, G. (2020). A methane sink in the Central American high elevation paramo: Topographic, soil moisture and vegetation effects. Geoderma, 362, 114092. https://doi.org/10.1016/j.geoderma.2019.114092

Correa, A., Ochoa-Tocachi, B.F., Birkel, C., et al. (2020). A concerted research effort to advance the hydrological understanding of tropical paramos. Hydrological Processes, 34, 4609-4627. https://doi.org/10.1002/hyp.13904

Dansgaard, W. (1964). Stable isotopes in precipitation. Tellus, 16(4), 436-468. https://doi.org/10.3402/tellusa.v16i4.8993

Esquivel-Hernandez, G., Sanchez-Murillo, R., Birkel, C., Good, S. P., Boll, J. (2017). Hydroclimatic and ecohydrological resistance/resilience conditions across tropical biomes of Costa Rica. Ecohydrology. 10 (6), e1860. https://doi.org/10.1002/eco.1860

Esquivel-Hernandez, G., Sanchez-Murillo, R., Quesada-Roman, A., Mosquera, G.M., Birkel, C., Boll, J. (2018). Insight into the stable isotopic composition of glacial lakes in a tropical alpine ecosystem: Chirripo, Costa Rica. Hydrological Processes, 32, 3588-3603. https://doi.org/10.1002/hyp.13286

Esquivel-Hernandez, G., Mosquera, G. M., Sanchez-Murillo, R., Quesada-Roman, A., Birkel, C., Crespo, P., 
... Boll, J. (2019). Moisture transport and seasonal variations in the stable isotopic composition of rainfall in Central American and Andean Paramo during El Nino conditions (2015-2016). Hydrological Processes, 33, 1802-1817. https://doi.org/10.1002/hyp.13438

Magana, V., Amador, J. A., \& Medina, S. (1999). The midsummer drought over Mexico and Central America. Journal of Climate, 12(1967), 1577-1588. https://doi.org/10.1175/15200442(1999)012<1577:TMDOMA > 2.0.CO;2

Sanchez-Murillo, R., Esquivel-Hernandez, G., Corrales-Salazar, J. L., Castro-Chacon, L., DuranQuesada, A. M., Guerrero-Hernandez, M., ... Terzer-Wassmuth, S. (2020a). Tracer hydrology of the data-scarce and heterogeneous Central American Isthmus. Hydrological Processes. 34, 2660-2675. https://doi.org/10.1002/hyp.13758

Sanchez-Murillo, R., Esquivel-Hernandez, G., Birkel, C., Correa, A., Welsh, K., Duran-Quesada, A.M., Sanchez-Gutierrez, R., Poca, M. (2020b). Tracing Water Sources and Fluxes in a Dynamic Tropical Environment: From Observations to Modeling. Frontiers in Earth Science, 8, 438. https://doi.org/10.3389/feart.2020.571477

Viviroli, D., Durr, H. H., Messerli, B., Meybeck, M., and Weingartner, R. (2007). Mountains of the world, water towers for humanity: Typology, mapping, and global significance. Water Resources Research, 43, W07447. https://doi.org/10.1029/2006WR005653

Waylen, M. E. (1996). Interannual variability of monthly precipitation in Costa Rica. Journal of Climate, 9, 2606-2613. https://doi.org/10.1175/1520-0442(1996)009<2606:IVOMPI >2.0.CO;2

Wright, C., Kagawa-Viviani, A., Gerlein-Safdi, C., Mosquera, G. M., Poca, M., Tseng, H., Chun, K. P. (2017). Advancing ecohydrology in the changing tropics: Perspectives from early career scientists. Ecohydrology, 11, e1918. https://doi.org/10.1002/eco.1918

Wu, J., Porinchu, D.F., Horn, S.P. (2019a). Late Holocene hydroclimate variability in Costa Rica: Signature of the terminal classic drought and the Medieval Climate Anomaly in the northern tropical Americas. Quaternary Science Reviews, 215, 144-159. https://doi.org/10.1016/j.quascirev.2019.04.023

Wu, J., Porinchu, D.F., Campbell, N.L., Mordecai, T.M., Alden, E.C. (2019b). Holocene hydroclimate and environmental change inferred from a high-resolution multi-proxy record from Lago Ditkebi, Chirripo National Park, Costa Rica. Palaeogeography, Palaeoclimatology, Palaeoecology, 518, 172-186. https://doi.org/10.1016/j.palaeo.2019.01.004

Table 1. Summary statistics of environmental conditions (Lake Ditkevi average daily water temperature, average daily air temperature, and daily precipitation amount) and stable isotope composition of precipitation, lake water and stream water for the period April 2015-November 2020.

\begin{tabular}{llll}
\hline & Environmental conditions & Environmental conditions & Environmental cc \\
\hline Parameter & $\mathrm{N}$ & Average & Median \\
Lake Ditkevi water temperature $\left({ }^{\circ} \mathrm{C}\right)$ & 1881 & 11.9 & 11.9 \\
Rainfall $(\mathrm{mm} /$ day $)$ & 1948 & 6.1 & 1.6 \\
Air temperature $\left({ }^{\circ} \mathrm{C}\right)$ & 1825 & 11.0 & 9.6 \\
Relative humidity $(\%)$ & 1825 & 77 & 83 \\
& $\delta^{18} \mathrm{O}\left(\delta^{18} \mathrm{O}\left(\delta^{18} \mathrm{O}\right.\right.$ (Type of sample & $\mathrm{N}$ & Average \\
$\mathrm{SD}$ & & & \\
Precipitation & 512 & -10.60 & -10.36 \\
Lake Chirripó & 48 & -9.84 & -9.78 \\
Lake Ditkevi & 66 & -9.06 & -9.21 \\
Lake Morrenas & 38 & -9.06 & -9.65 \\
Stream water & 74 & -11.15 & -11.19
\end{tabular}




\begin{tabular}{llll}
\hline & Environmental conditions & Environmental conditions & Environmental c \\
\hline SD & $\delta^{2} \mathrm{H}\left(\delta^{2} \mathrm{H}\left(\delta^{2} \mathrm{H}\right.\right.$ (Type of sample & $\mathrm{N}$ & Average \\
Precipitation & & & -71.56 \\
Lake Chirripó & 512 & -73.98 & -70.34 \\
Lake Ditkevi & 48 & -71.78 & -66.11 \\
Lake Morrenas & 66 & -64.89 & -69.49 \\
Stream water & 38 & -66.23 & -78.34 \\
& 74 & -78.08 & Average \\
SD & $d$-excess $(d$-excess $(($ Type of sample & $\mathrm{N}$ & 11.12 \\
Precipitation & & & 5.99 \\
Lake Chirripó & 512 & 10.79 & 8.04 \\
Lake Ditkevi & 48 & 6.91 & 7.62 \\
Lake Morrenas & 66 & 7.57 & 11.00 \\
Stream water & 38 & 6.28 & 11.17 \\
\hline
\end{tabular}

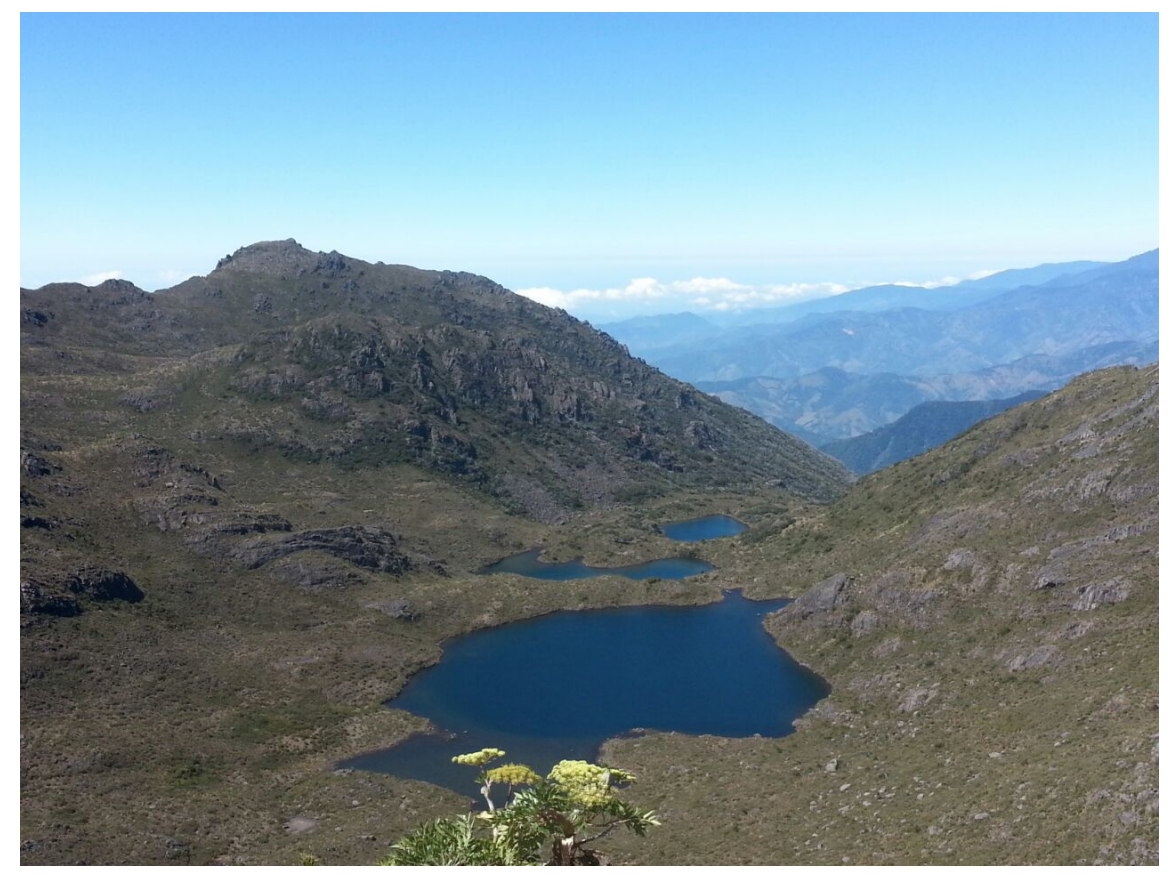



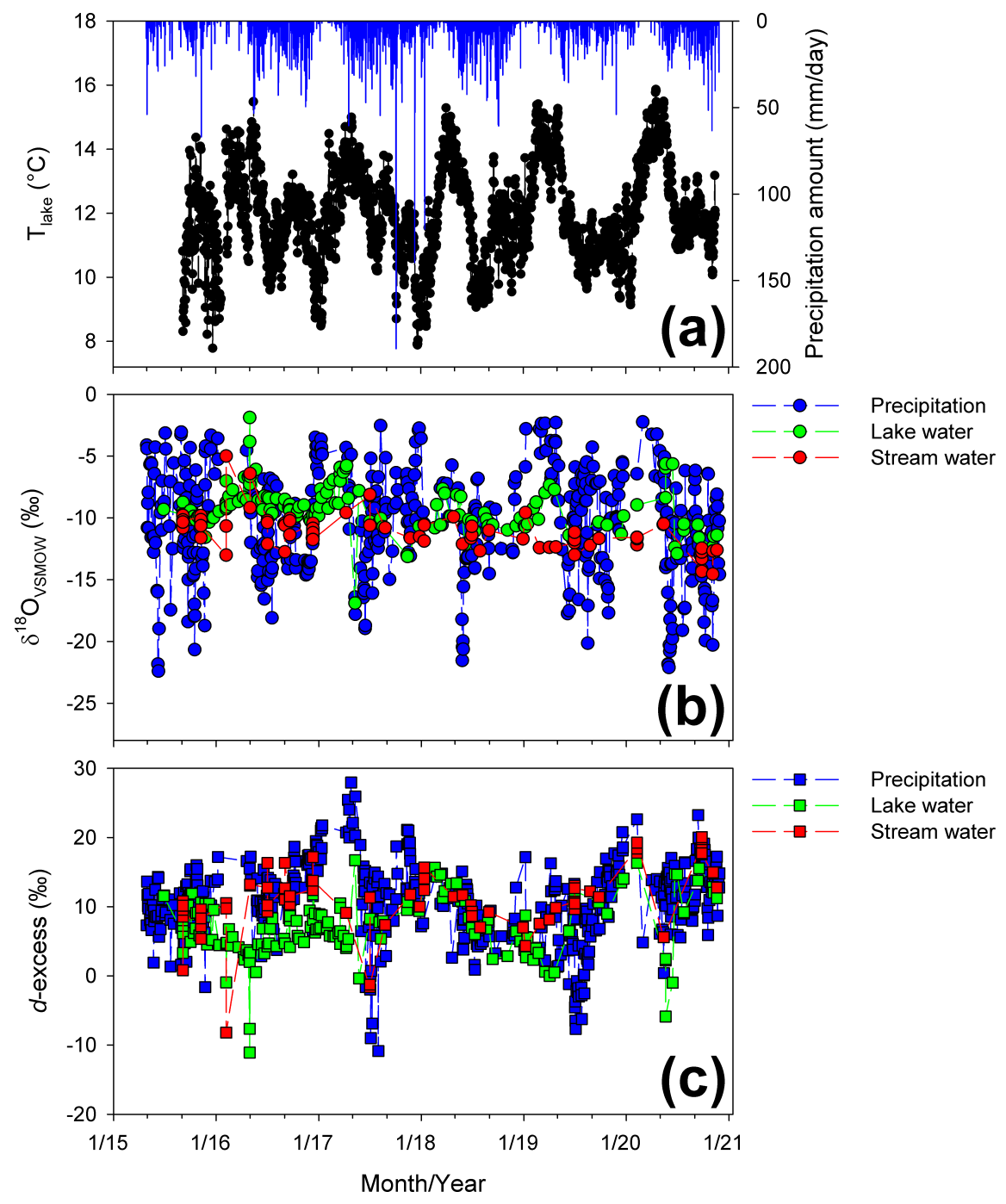

Precipitation Lake water Stream water 


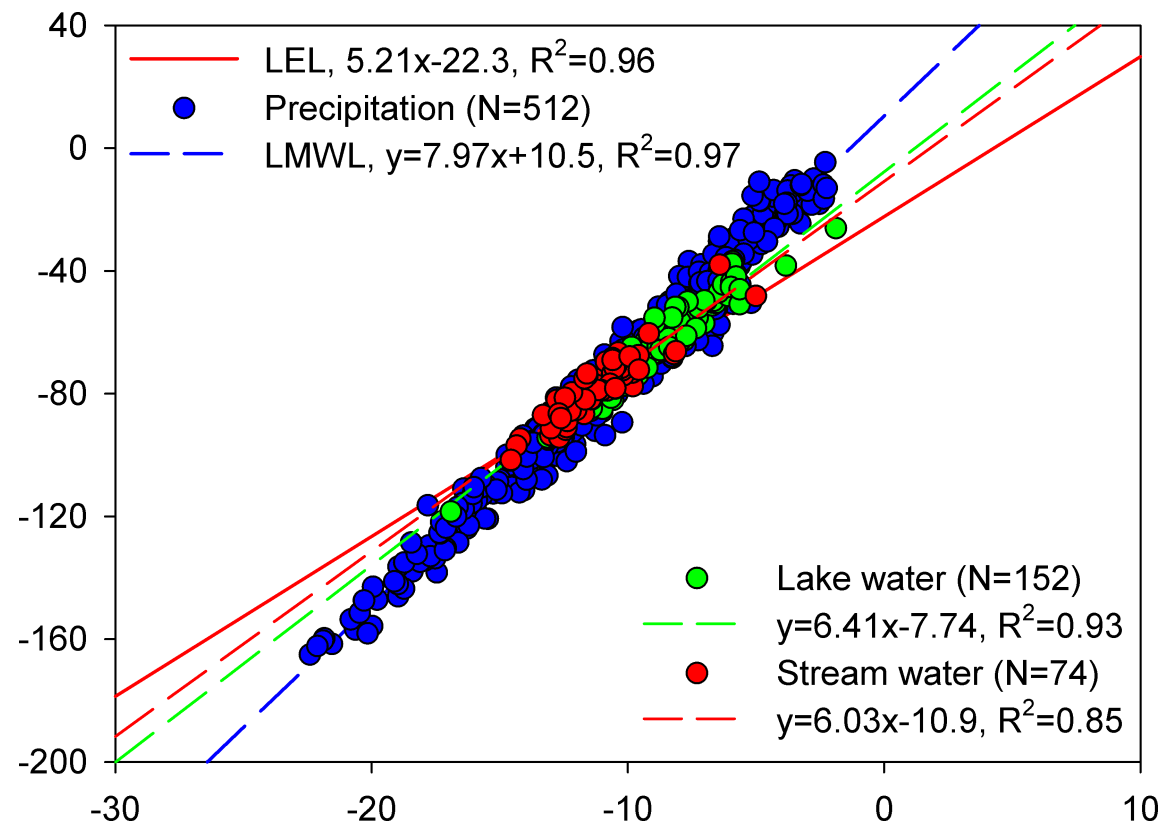

